\title{
Molecular Depiction Of lepA, lidA, ralF, rtxA And IvhB Virulence Factors Of Legionella Pneumophila Isolated From Respiratory Tract Infections

\author{
Forouzan Khedri ${ }^{1}$, Fatemeh Alaei Faradonbeh ${ }^{1 *}$, Mahvash Eliyasi ${ }^{1}$, \\ Anahita Barghi ${ }^{1}$, Abbas Doosti ${ }^{2}$, Pardis Emad ${ }^{1}$, Aida Alaei Faradonbeh ${ }^{3}$
}

\section{Abstract}

Background: Among all bacterial species in the genus Legionella, Legionella pneumophila is responsible for $90 \%$ of Legionella infections in humans. Putative virulence genes are the main factors in pathogenesis of $L$. pneumophila. The aim of this study was to determine the incidence of $L$. pneumophila in the broncho alveolar lavages of patients hospitalized due to respiratory tract infections as well as study the distribution of lepA, lidA, ralF, rtxA and I vhB virulence factors in bacterial strains.

Methods: One hundred fifty BAL samples were collected from patients who were referred to several Iranian health centers. Samples were cultured and those that were $L$. pneumophila positive were subjected to PCR method targeting the 16S rRNA gene. Samples positive for Legionella were analyzed for presence of latent virulence factors.

Results: Thirteen out of 90 male BAL samples (14.4\%) and 5 out of 60 female BAL samples (8.3\%) were positive for L. pneumophila $(P=0.046)$. Patients older than 50 years had the highest incidence of $L$. pneumophila (20\%), while patients younger than 15 years old had the lowest $(4.16 \%)(P=0.017)$. All patients positive for $L$. pneumophila had fever, while the distribution of cough, dyspnea, chest pain and headache were $77.7 \%, 77.7 \%, 66.6 \%$ and $44.4 \%$, respectively. The most commonly detected virulence factors among L. pneumophila isolates were lidA (50\%) and ralF (27.77\%).
1 Graduate Student of Microbiology, College of Basic Science, Islamic Azad University, Shahrekord Branch, Shahrekord, Iran.

2 Biotechnology Research Center, College of Basic Science, Islamic Azad University, Shahrekord Branch, Shahrekord, Iran.

3 Student of Molecular and Cellular Biology, College of Basic Science, Razi University, Kermanshah Branch, Kermanshah, Iran.

\section{Contact information:}

Fatemeh Alaei Faradonbeh (BS, MSC) Department of Microbiology, College of Basic Science, Islamic Azad University, Shahrekord Branch, Shahrekord, Iran

Tel: 982819070

Fax: 983834226338

”f_alaei67@yahoo.com 
Conclusion: Results indicate that sex and age of patients and climate conditions may constitute risk factors for incidence of $L$. pneumophila. Due to the high prevalence of $L$. pneumophila, wide-ranging amendments should be done in the principles of clinical care in some Iranian hospitals.

\section{Keywords}

Legionella pneumophila, Prevalence, Broncho Alveolar Lavages, Respiratory infections, Risk factors

\section{Background}

Respiratory Tract Infections (RTIs) are the most common, and possibly most severe clinically infectious diseases. There were 3,084 deaths attributable to RTIs and pneumonia in recent years in developed countries like Australia [1]. RTIs accounted for a total of 43,953 hospital admissions with an average length of stay of 6.3 days [1]. RTIs are usually caused by viruses, however the roles of bacteria are also significant. One of the most commonly considered pathogens in the cases of RTIs and pneumonia is Legionella species (Legionella spp.). Although several species of the genus Legionella were subsequently identified in the cases of RTIs, Legionella pneumophila (L. pneumophila) is the most frequent cause of human legionellosis or Legionnaires Disease (LD) and also a comparatively common cause of community-acquired and nosocomial pneumonia in adults [2]. In children, L pneumophila is also a significant, although quite scarce, cause of pneumonia. It has been estimated that 18,000 patients are admitted annually in the United States due to the LD which is quite significant [3].

L. pneumophila are gram-negative, fastidious and aerobic bacilli, catalase-positive, heterotrophic, motile, non-fermentative and urease and nitrate negative bacterium [4]. RTIs caused by this bacterium are usually known by fever, confusion, headache, abdominal pain, diarrhea, chills, and myalgia as well as a non-productive cough [5]. Mortality rate of $L$. pneumophila RTIs is reported to be $15-25 \%[5,6]$.

Most outbreaks and sporadic cases of RTIs caused by L. pneumophila have been attributed to presence of certain virulence factors. The products of genes are involved in the initial attachment to host cells and early stages of intracellular infection like the pore formation protein $r t x A$ [7]. Another group of genes are those required for bacterial survival and intracellular replication like a number of effectors including ralF, lidA and lepA [8]. Legionella vir homolog (Ivh) is a type IV secretion system involved in conjugation $[8,9]$. Another important virulence factor is legAS4. LegAS4 contained an active SET domain that methylated H3. Previous bioinformatics efforts have identified LegAS4 as a putative secreted effector owing to the presence of a eukaryotic specific ankyrin repeat domain [7-9]. The amino terminus of LegAS4 also contained a SET domain and tandem nuclear localization signals (NLS). LegAS4 was efficiently translocated from $L$. pneumophila into host macrophages.

The epidemiology and prevalence of $L$. pneumophila and its virulence factors in BAL samples are essentially unknown in Iran. From a clinical, microbiological and epidemiological perspective, it is important to know the exact prevalence of $L$. pneumophila among clinical samples taken from patients suffering from RTIs. It is also important to know 
which virulence genes are present in L. pneumophila strains of RTIs. The above goals were addressed in the present investigation.

\section{Methods}

\section{Samples}

From November to March 2013, a total of 150 Broncho Alveolar Lavage (BAL) samples were collected from patients suffering from RTIs using bronchoscopy. Patients were referred to some Iranian health centers including Baqiat-Allah hospital (Tehran, Iran), Hajar Hospital (Shahrekord, Iran) and some educational hospitals of Iran in Isfahan, Tehran, Shiraz and etc. At the time of sampling, information about the age, sex and clinical symptoms of the patients were recorded. Ten $\mathrm{ml}$ of each sample was immediately transferred to a sterile falcon tube containing ice and was immediately transferred to the Biotechnology Research Center of the Islamic Azad University of Shahrekord.

\section{Bacterial isolation}

Prior to culture, BAL samples were centrifuged for $15 \mathrm{~min}$ at 2,500 rpm, and the top $7.5 \mathrm{ml}$ of the resulting suspension was removed. The remaining cell concentrate was mixed and used for culture. Aliquots of $100 \mu \mathrm{L}$ of prepared samples were spread on duplicate plates of aBCYE selective medium Agar (Difco Laboratories, Detroit, Mich., USA) and to plates containing L-cysteine $\left(0.44 \mathrm{mg} \mathrm{mL}^{-1}\right)$, ferric pyrophosphate $\left(0.250 \mathrm{mg} \mathrm{mL}^{-1}\right)$, glycine (3.0 $\left.\mathrm{gL}^{-1}\right)$, vancomycin $\left(0.0025 \mathrm{mg} \mathrm{mL}^{-1}\right)$ and polymyxin $B\left(0.006 \mathrm{mgmL}^{-1}\right)$, which are named $\alpha B C Y E-G V P$ selective agar medium. Plates were incubated at $37^{\circ} \mathrm{C}$ in a humidified atmosphere without $\mathrm{CO} 2$ during 5 days. Colonies with the typical ground glass appearance of Legionella were sub cultured on two nonselective media, sheep-blood agar and $\alpha B C Y E$ agar without L-cysteine. Colonies that grew on $\alpha B C Y E-$ GVP but not on non-selective media were consi- dered putative Legionella strains, and were Gram stained and subcultured on a selective medium. The identification of putative Legionella strains as $L$. pneumophila was carried out using Legionella specific latex reagents (Oxoid, Hampshire, England) and direct immunofluorescence assay with poly clonal rabbit sera (m-Tech Alpharetta, Ga., USA).

\section{DNA extraction and PCR amplification for 16S ribosomal RNA gene}

L. pneumophila isolates were submitted to DNA extraction using the DNA extraction kit (Fermentas, Germany), according to the manufacturer's instructions. Set of novel primers for $16 \mathrm{~S}$ ribosomal RNA (16S rRNA) gene of the L. pneumophila was designed by authors. Recorded sequences of the 16S rRNA gene of the L. pneumophila have been gotten from the GenBank database of the National Center for Biotechnology Information (NCBI) (ACCESSION AB811078). The CLS sequence viewer software (Version 6/4) has been used for alignments of the 165 rRNA gene. Forward and reverse primers have been designed based on the protected area in these sequences. Thermodynamic properties of designed primers were studied using the Gene Runner software (Version 3.05). In order to ensure the specificity of designed primers, the Basic Logical Alignment Search Tool (BLAST) service, has been used. The extracted DNA of each sample was kept frozen at $-20^{\circ} \mathrm{C}$ until used. Primer sequences used for PCR, Legionella-F: 5' GCTAATACCGCATAATGTCTGAGG-3' and Legionella-R: GGTGCTTCTGTGGGTAACG-3' were designed from 16S ribosomal RNA gene of Legionella (ACCESSION AB811078). $P C R$ reactions were performed in a total volume of $25 \mu \mathrm{L}$, including $1.5 \mathrm{mM} \mathrm{MgCl} 2,50 \mathrm{mM} \mathrm{KCl}$, $10 \mathrm{mM}$ Tris- $\mathrm{HCl}(\mathrm{pH} 9.0), 0.1 \%$ Triton X-100, 200 $\mu \mathrm{M}$ dNTPs each (Fermentas, Germany), 25 pmoL of each primers, $1.5 \mathrm{U}$ of Taq DNA polymerase (Fermentas, Germany), and $3 \mu \mathrm{L}(40-260 \mathrm{ng} / \mu \mathrm{L})$ of DNA. The samples were placed in a thermal cycler (Mastercycler gradient, Eppendorf, Germany) with 
an initial denaturation step at $95^{\circ} \mathrm{C}$ for $5 \mathrm{~min}$, then amplified for 30 cycles of denaturation at $94^{\circ} \mathrm{C}$ for 1 min, annealing at $62^{\circ} \mathrm{C}$ for 1 min, extension at $72^{\circ} \mathrm{C}$ for $1 \mathrm{~min}$ and final extension step at $72^{\circ} \mathrm{C}$ for $5 \mathrm{~min}$.

\section{Detection of virulence factors of Legionella pneumophila}

Table 1 lists the primers used for detection of lepA, lidA, ralF, rtxA and IVhB virulence factors of $L$. pneumophila and program and the condition for each

Table 1. IThe oligonucleotide primers and the PCR programs used for amplification of lepA, lidA, ralF, rtxA and $I v h B$ virulence factors of $L$. pneumophila isolated from BAL samples.

\begin{tabular}{|c|c|c|c|c|}
\hline $\begin{array}{c}\text { PCR } \\
\text { Volume } \\
(50 \mu \mathrm{L})\end{array}$ & Primer sequence $\left(5^{\prime}-3^{\prime}\right)^{*}$ & $\begin{array}{c}\text { PCR } \\
\text { product } \\
\text { (bp) }\end{array}$ & PCR programs & PCR Volume $(50 \mu \mathrm{L})$ \\
\hline lepA & $\begin{array}{l}\text { F: GTTGGGCACTACAGTTATCTCTTC } \\
\text { R: GTTAGTTACTACGGTTTCAATACGAC }\end{array}$ & 354 & 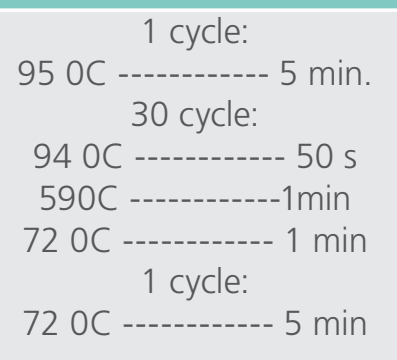 & $\begin{array}{c}5 \mu \mathrm{L} \text { PCR buffer 10X } \\
2 \mathrm{mM} \text { Mgcl2 } \\
150 \mu \mathrm{M} \text { dNTP (Fermentas) } \\
0.75 \mu \mathrm{M} \text { of each primers F \& R } \\
1.5 \mathrm{U} \text { Taq DNA polymerase } \\
\text { (Fermentas) } \\
3 \mu \mathrm{L} \text { DNA template }\end{array}$ \\
\hline $\operatorname{lid} A$ & $\begin{array}{l}\text { F: CACAGGCTAAGGAAGACAGAGGC } \\
\text { R: TAATTTCCTTGACTTTTTCCGCAG }\end{array}$ & 270 & 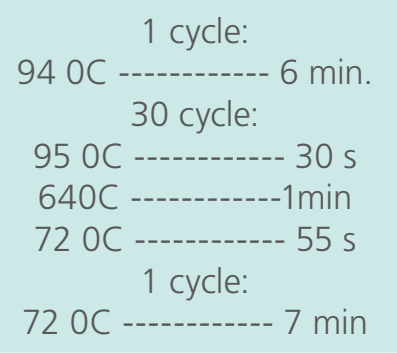 & $\begin{array}{c}5 \mu \mathrm{L} \text { PCR buffer 10X } \\
2 \mathrm{mM} \text { Mgcl2 } \\
150 \mu \mathrm{M} \text { dNTP (Fermentas) } \\
0.75 \mu \mathrm{M} \text { of each primers } \mathrm{F} \& \mathrm{R} \\
1.5 \cup \text { Taq DNA polymerase } \\
\text { (Fermentas) } \\
3 \mu \mathrm{L} \text { DNA template }\end{array}$ \\
\hline ralf & $\begin{array}{l}\text { F: ACCAGCCCAGGATATGAACTTAC } \\
\text { R: ATAGTAGCTTGTGCGGATGTTTTG }\end{array}$ & 230 & 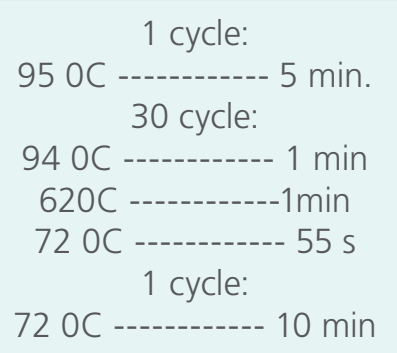 & $\begin{array}{c}5 \mu \mathrm{L} \text { PCR buffer 10X } \\
2 \mathrm{mM} \text { Mgcl2 } \\
200 \mu \mathrm{M} \text { dNTP (Fermentas) } \\
0.5 \mu \mathrm{M} \text { of each primers } \mathrm{F} \& \mathrm{R} \\
1.5 \mathrm{U} \text { Taq DNA polymerase } \\
\text { (Fermentas) } \\
5 \mu \mathrm{L} \text { DNA template }\end{array}$ \\
\hline$r t \times A$ & $\begin{array}{l}\text { F: ATTGCTTTTTCAGGTATCACTAACG } \\
\text { R: ATTCGTTGATGTACTAATAGGCTGG }\end{array}$ & 265 & 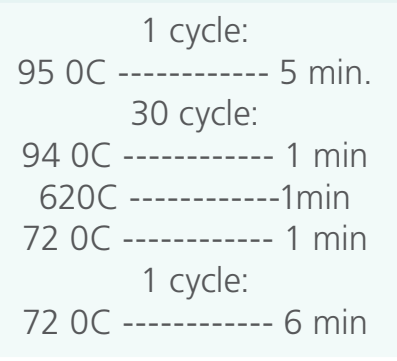 & $\begin{array}{c}5 \mu \mathrm{L} \text { PCR buffer 10X } \\
2 \mathrm{mM} \text { Mgcl2 } \\
150 \mu \mathrm{M} \text { dNTP (Fermentas) } \\
0.75 \mu \mathrm{M} \text { of each primers F \& R } \\
1.5 \mathrm{U} \text { Taq DNA polymerase } \\
\text { (Fermentas) } \\
3 \mu \mathrm{L} \text { DNA template }\end{array}$ \\
\hline IVhB & $\begin{array}{l}\text { F: GTCAAACAACTTCATTCAAACACC } \\
\text { R: GGCAATAAATTCACAATCCAGAG }\end{array}$ & 272 & 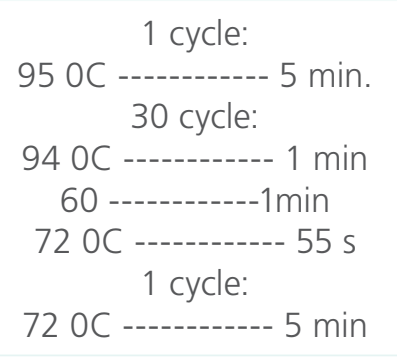 & $\begin{array}{c}5 \mu \mathrm{L} \text { PCR buffer 10X } \\
2.5 \mathrm{mM} \text { Mgcl2 } \\
200 \mu \mathrm{M} \text { dNTP (Fermentas) } \\
0.5 \mu \mathrm{M} \text { of each primers } \mathrm{F} \& \mathrm{R} \\
2 \mathrm{U} \text { Taq DNA polymerase } \\
\text { (Fermentas) } \\
3 \mu \mathrm{L} \text { DNA template }\end{array}$ \\
\hline
\end{tabular}


Table 2. Total distribution of $L$. pneumophila in the BAL samples of male and female patients with respiratory infections.

\begin{tabular}{|c|c|c|c|}
\hline Gender & Age (Year) & $\begin{array}{l}\text { No. samples } \\
\text { collected }\end{array}$ & $\begin{array}{l}\text { Distribution of } L \text {. } \\
\text { pneumophila }(\%)\end{array}$ \\
\hline \multirow{5}{*}{ Male } & $15>$ & 12 & $1(8.33)$ \\
\hline & $15-30$ & 22 & $2(9.09)$ \\
\hline & $30-50$ & 26 & $4(15.38)$ \\
\hline & $50<$ & 30 & $7(23.33)$ \\
\hline & Total & 90 & $13(14.44)$ \\
\hline \multirow{5}{*}{ Female } & $15>$ & 12 & - \\
\hline & $15-30$ & 14 & - \\
\hline & $30-50$ & 14 & $1(14.28)$ \\
\hline & $50<$ & 20 & $3(15)$ \\
\hline & Total & 60 & $5(8.33)$ \\
\hline \multirow{5}{*}{ Total } & $15>$ & 24 & $1(4.16)$ \\
\hline & $15-30$ & 36 & $2(5.55)$ \\
\hline & $30-50$ & 40 & $5(12.5)$ \\
\hline & $50<$ & 50 & $10(20)$ \\
\hline & Total & 150 & $18(12)$ \\
\hline
\end{tabular}

reaction. A DNA thermo-cycler (Mastercycler gradient, Eppendorf, Germany) was also used in all PCR reactions.

\section{Gel electrophoresis}

The PCR amplification products $(10 \mu \mathrm{l})$ were subjected to electrophoresis in a 1\% agarose gel in 1X TBE buffer at $80 \mathrm{~V}$ for $30 \mathrm{~min}$, stained with ethidium bromide, and images were obtained in a UVIdoc gel documentation system (UK). The PCR products were identified by 100 bp DNA size marker (Fermentas, Germany). A DNA of L. pneumophila ATCC 33152 was used as positive control and DNA of a laboratory isolate strain of $E$. coli as negative control.

\section{Sequencing}

In order to confirm the PCR results, the sequencing method was used. For this reason, PCR products of some positive samples were purified with High pure PCR product purification kit (Roche Applied Science, Germany) according to manufacturer's recommendations. Single DNA strands were sequenced with $A B I 3730 \mathrm{XL}$ device and Sanger sequencing method (Macrogen, Korea). Result of the sequence of each gene was aligned with the gene sequences recorded in the GenBank database located at NCBI.

\section{Statistical analysis}

The data were analyzed using SPSS (Statistical Package for the Social Sciences) software and $P$ values were calculated using Chi-square and Fisher's exact tests to identify statistically significant relationships for the distribution of $L$. pneumophila and putative genes between various studied groups of patients. A $P$ value $<0.05$ was considered statistically significant.

\section{Ethical issues}

The present study was authorized by the ethical committee of the education health care centers of the Shahrekord city, Iran, and the Biotechnology Research Center of the Islamic Azad University of Shahrekord Branch, Iran. All patients or their parents signed the written informed consent.

\section{Results and discussion}

Table 1 shows the distribution of L. pneumophila in patients suffering from respiratory infections. Of 150 BAL samples studied, 18 samples (12\%) were positive for L. pneumophila. In the other hand, 13 out of 90 male BAL samples (14.4\%) and 5 out of 60 female BAL samples (8.3\%) were positive for $L$. pneumophila. There were significant differences $(P$ $=0.046$ ) in the incidence of $L$. pneumophila between male and female patients. We found that the over 50 years old patients had the highest incidence of L. pneumophila (20\%), while the less than 15 years old children had the lowest incidence (4.1\%). There also were significant differences $(P=0.017)$ 
in the incidence of $L$. pneumophila between young and old patients.

Total incidence of $L$. pneumophila based on the clinical signs of patients is shown in table 3 . We found that all of the positive patients had fever, while $7.6 \%$ of male patients had nausea. The most commonly recorder clinical signs in patients suffered from respiratory infections caused by $L$. pneumophila were cough $(77.7 \%)$, dyspnea $(77.7 \%)$, chest pain $(66.6 \%)$ and headache (44.4\%). There were no female patient with nausea and myalgia. We found a statistically significant association between the incidence of fever and abdominal pain ( $P=0.009$ ), cough and nausea $(P=0.012)$, chest pain and diarrhea $(P=0.035)$ and dyspnea and myalgia $(P=0.019)$ in patients infected with $L$. pneumophila.

Table 3. Total Distribution of $L$. pneumophila with respect to the various clinical symptoms.

\begin{tabular}{|c|c|c|c|}
\hline \multirow{2}{*}{ Gender } & \multicolumn{3}{|c|}{ Total positive for L. pneumophila (\%) } \\
\cline { 2 - 4 } & Male & Female & Total \\
\hline Fever & $13(100)$ & $5(100)$ & $18(100)$ \\
\hline Cough & $10(76.92)$ & $4(80)$ & $14(77.77)$ \\
\hline Chest pain & $8(61.53)$ & $4(80)$ & $12(66.66)$ \\
\hline Dyspnea & $10(76.92)$ & $4(80)$ & $14(77.77)$ \\
\hline Headache & $5(38.46)$ & $3(60)$ & $8(44.44)$ \\
\hline Diarrhea & $3(23.07)$ & $1(20)$ & $4(22.22)$ \\
\hline Nausea & $1(7.69)$ & - & $1(5.55)$ \\
\hline Abdominal pain & $3(23.07)$ & $1(20)$ & $4(22.22)$ \\
\hline Myalgia & $2(15.38)$ & - & $2(11.11)$ \\
\hline Total & $13(14.44)$ & $5(8.33)$ & $18(12)$ \\
\hline
\end{tabular}

Results of the gel electrophoresis for identification of putative virulence factors in the $L$. pneumophila isolates are shown in figure 1-4. Table 4 shows the distribution of putative virulence factors in patients suffering from $L$. pneumophila respiratory infections. The most commonly detected virulence factors among $L$. pneumophila isolates were lidA (50\%), followed by ralF (27.7\%). Totally, males had a higher incidence of virulence factors than females but there were no statistically significant differences between these two groups. There were significant differences between the incidence of lid $A$ and lepA ( $P=0.028)$, lid $A$ and ralF $(P=0.042)$, lid $A$ and $r t x A$ $(P=0.021)$ and lid $A$ and $\operatorname{lvh} B(P=0.033)$ virulence factors.

The incidence of $L$. pneumophila and its putative virulence factors in the BAL samples of patients suffering from RTIs has been investigated in the present study. Results showed that $14.4 \%$ of male and $8.3 \%$ of female patients were infected with L. pneumophila. One possible explanation for the higher prevalence of $L$. pneumophila in male than female patients is that men usually have more contact with the external contaminated environment. They work outside the house but women usually stay at home and are not in close contact with outside. In fact, most of the Iranian women prefer to work at home. In a study conducted by Ngeow et al. (2005) [10] 1800 patients were analyzed for presence of respiratory pathogens. Totally, 1756 patients with a diagnosis of CAP were enrolled in their investigation, comprising 1263 adults and 493 children. Total prevalence of respiratory patho-

Table 4. Distribution of $L$. pneumophila in the BAL samples of hospitalized male and female patients with and without history of smoking.

\begin{tabular}{|c|c|c|c|c|c|c|c|}
\hline \multirow{2}{*}{$\begin{array}{c}\text { Types of samples } \\
\text { (No samples) }\end{array}$} & \multirow{2}{*}{ No. positive (\%) } & \multicolumn{4}{|c|}{ Distribution of putative virulence factors (\%) } \\
\cline { 3 - 7 } & & lepA & lidA & ralF & rtxA & IvhB \\
\hline Male (90) & $13(14.44)$ & $2(15.38)$ & $7(53.84)$ & $4(30.76)$ & $1(7.69)$ & $2(15.38)$ \\
\hline Female (60) & $5(8.33)$ & - & $2(40)$ & $1(20)$ & - & $1(20)$ \\
\hline Total (150) & $18(12)$ & $2(11.11)$ & $9(50)$ & $5(27.77)$ & $1(5.55)$ & $3(16.66)$ \\
\hline
\end{tabular}


Figure 1: Results of the gel electrophoresis for identification of ralF and lepA genes of the L. pneumophila strains. M: 100 bp DNA ladder (Fermentas, Germany), Line 1: Positive control, Line 2: Positive sample for ralF gene (230 bp), Line 3: Positive control and Line 4: Positive sample for lepA gene (354 bp).

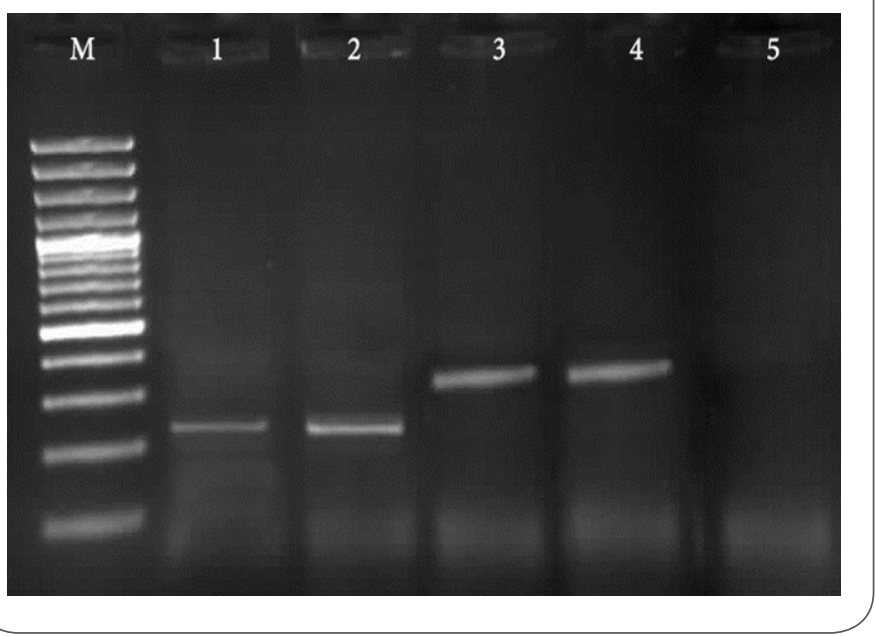

Figure 2: Results of the gel electrophoresis for identification of IVhB gene of $L$. pneumophilain BAL samples, M:100 bp DNA ladder (Fermentas, Germany), Lane 1: Positive control, 2: Positive samples for IVhB gene (272 bp) and Line 4 3: Negative control.

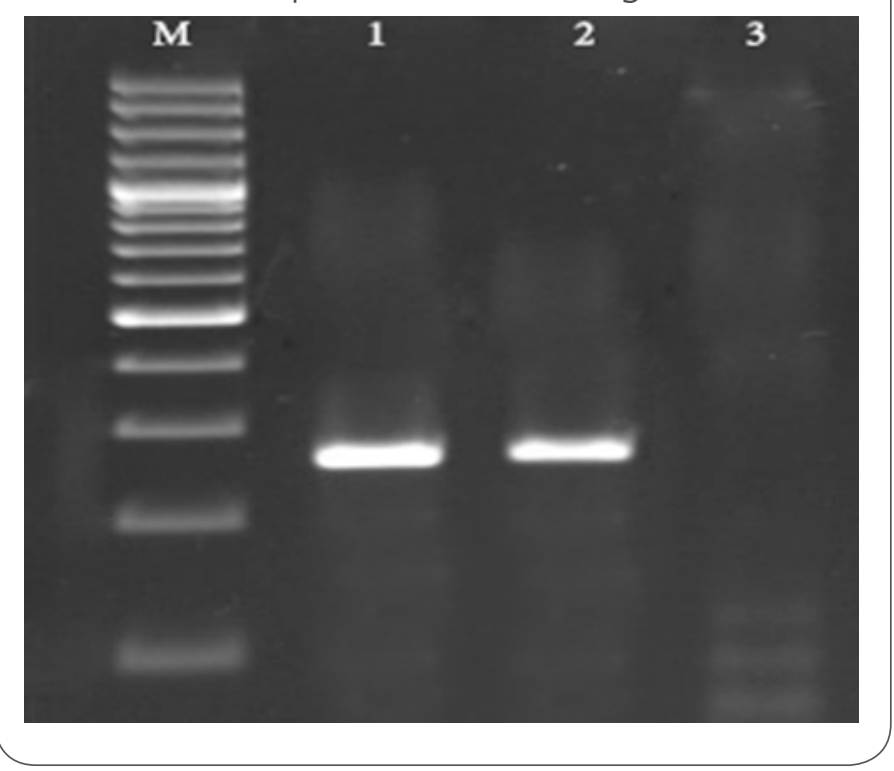

Figure 3: Results of the gel electrophoresis for identification of lidA gene of $L$. pneumophila in BAL samples, M:100 bp DNA ladder (Fermentas, Germany), Lane 1: Positive control, 2: Positive samples for lidA gene (270 bp band) and Line 3: Negative control.

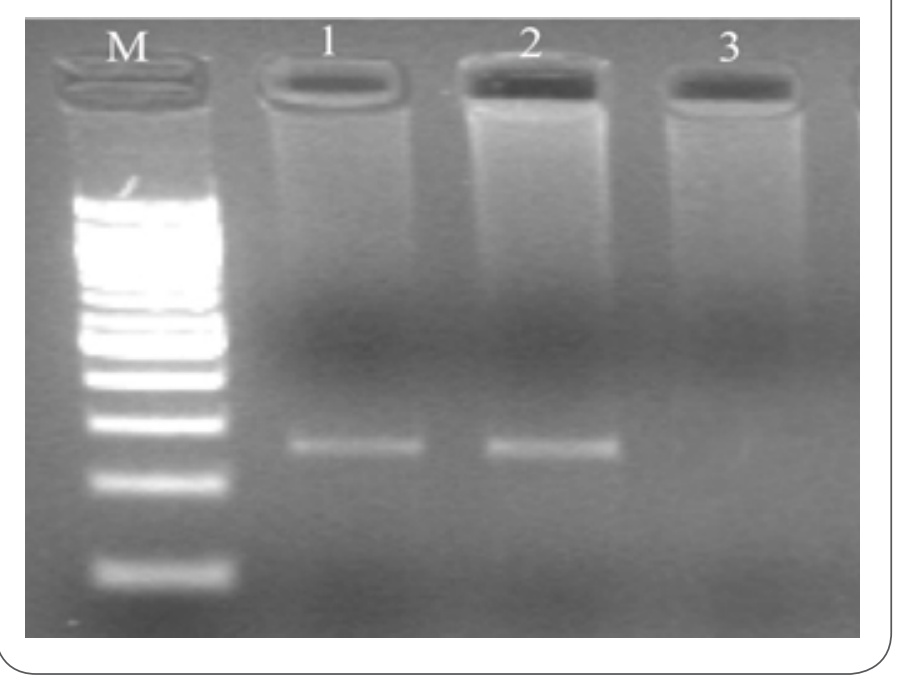

Figure 4: Results of the gel electrophoresis for identification of $r$ txA gene of $L$. pneumophila in BAL samples, M:100 bp DNA ladder (Fermentas, Germany), Lane 1: Positive control, Line 2: Positive samples for $r t x A$ gene (265 bp band) and Line 3: Negative control.

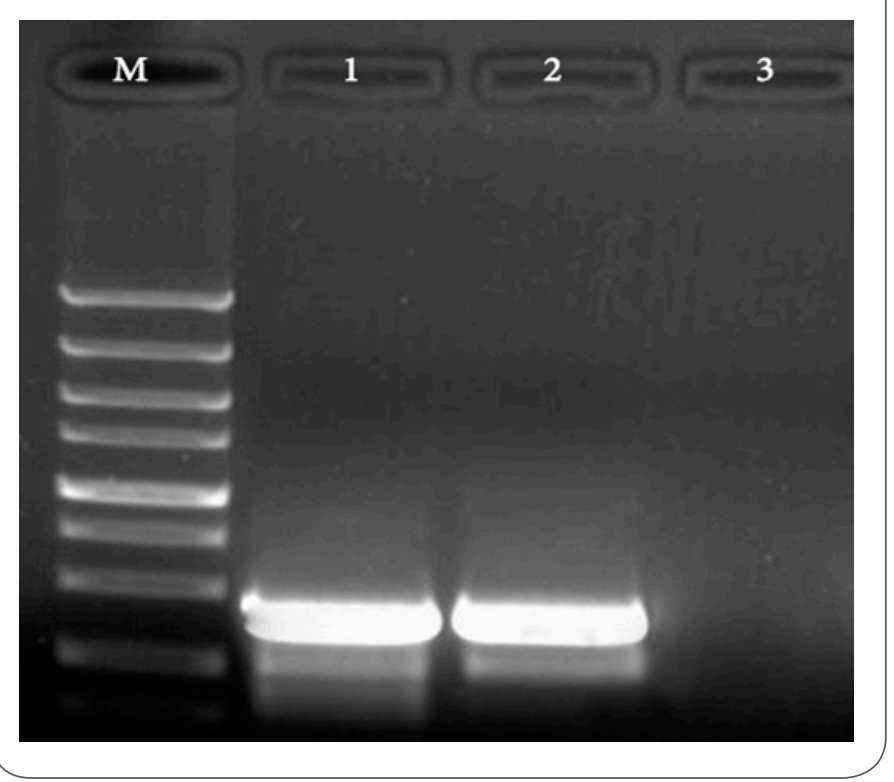


gens in the male and female patients of adults and children groups were 537 and 389 and 245 and 203, respectively which showed a higher incidence of respiratory pathogens in male patients. Similar results have been reported by Nagalingam et al. (2005) [11] and Amemura-Maekawa et al., (2010) [12]. These differences observed between the two sexes are consistent with animal and human studies [13]. Smoking and alcoholism are commonly acknowledged to be predisposing factors for legionellosis [14]. Smoking and alcoholism are more prevalent in male than female in Iran. Our results showed that 10 out of 13 male $(76.92 \%)$ and 3 out of 5 female $(60 \%)$ patients had the history of smoking in their life.

Total incidence of $L$. pneumophila in the BAL samples of our study were 12\% (18/150). Climatic variables such as heat, thunderstorms and rain, together with variable barometric pressure may have affected the patients' autonomic nervous systems and causes to high incidence of $L$. pneumophila in our study. These variables might affect immunity, thus making people more susceptible to infections. Alternatively, the higher prevalence of $L$. pneumophila may be related to cold climate of the study region. The samples of our study were also collected from November to March which were the cold months of the year in Iran. Environmental factors such as high humidity and increased rainfall also increase the risk for legionellosis [15]. Herrera-Lara et al. (2013) [16] suggested that the highest incidence of community acquired pneumonia was in the cold seasons of the year. Another explanation for the high incidence of $L$. pneumophila in our study is that some health guidelines may have been ignored in Iranian hospitals.

Total prevalence of $L$. pneumophila in the clinical samples of our study were $12 \%$ which was higher than the results of Ghotaslou et al. (2013) (Iran, 2.85\%) [17] and Bozzoni et al. (1995) (Switzerland, $5.1 \%)$ [18], while was lower than the results of $\mathrm{Yu}$ et al. (2008) (Taiwan, 19\%) [19], Chaudhry et al.
(2000) (India, 13\%) [20], and Azara et al. (2006) (Italy, 26\%) [21]. Lim et al. (2001) [22] reported that of 309 patients hospitalized due to Community Acquired Pneumonia (CAP) 135 (50.60\%) were men and the prevalence of $L$. pneumophila was $3 \%$. A total of 202 patients hospitalized with a diagnosis of CAP were enrolled in a Korean study and 3 samples $(2.4 \%)$ were positive for $L$. pneumophila which also was lower than our results [23]. Total incidence of L. pneumophila in Southeast Asia was 0.28 cases per 100,000 population (0.1\%) [24], while its incidence among European countries were 1.18\% $(100,000$ cases in 2008) [25]. The above investigations highlight large differences in the prevalence of L. pneumophila. This could be related to differences in the type of sample (BAL, water of hospital, stool, blood, urine, and other clinical samples) tested, number of samples, method of sampling, season of sampling, experimental methodology, geographical area, and climate differences in the areas where the samples were collected, which would have differed between each study.

Our results also showed that patients older than 50 years had the highest incidence of L. pneumophila (20\%), while patients younger than 15 years old had the lowest incidence (4.1\%). Nagalingam et al. (2005) [11] reported that hospitals, gender and ethnicity did not significantly $(P>0.05$; chisquared) affect the seroprevalence of $L$ pneumophila. However, Sopena et al. (2007) [26] showed that elderly patients with CAP caused by L. pneumophila had a higher frequency of underlying comorbidities and presented less frequently with fever and classical non respiratory symptoms and laboratory abnormalities of Legionnaires' disease than younger patients.

Among 18 positive patents for L. pneumophila in our study, the distribution of fever, cough, chest pain, dyspnea, headache, diarrhea, nausea, abdominal pain and myalgia were 100\%, 77.7\%, 66.6\%, $77.7 \%, 44.4 \%, 22.2 \%, 5.5 \%, 22.2 \%$ and $11.1 \%$, respectively. These symptoms have been reported 
previously as a common clinical signs of legionellosis caused by L. pneumophila [27]. Chon Lam et al. (2011) [24] reported that the main clinical features of reported cases of RTIs caused by L. pneumophila were cough $(77.9 \%)$, fever $(72.7 \%)$, shortness of breath (32.5\%), chest pain (13.3\%) and nausea $(11.8 \%)$ which was similar to our results.

To date, there were no exclusive investigation on the molecular detection of virulence factors among clinical isolates of $L$. pneumophila in Iran. The results of our study showed that the distribution of lepA, $\operatorname{lid} A$, ralF, rtxA and $I v h B$ virulence genes were $11.1 \%$ (2/18), 50\% (9/18), 27.7\% (5/18), 5.5\% (1/18) and $16.6 \%(3 / 18)$ with the higher prevalence in male patients with the exception of ralF and $I V h B$ gene. Huang et al. (2006) [28] showed that the incidence of Ivh and rtxA genes in patients with clinical manifestations of L. pneumophila were $57.6 \%$ and $64.4 \%$, respectively. RtxA positive strains of $L$. pneumophila have been shown to have a high capability to enter to monocytes and epithelial cells, and increased cytotoxicity and intracellular duplication [7]. An isolate with the rtxA gene would have improved abilities for attachment, intracellular growth and cytotoxicity. Consequently, isolates bearing either Ivh or $\operatorname{rtx} A$, or both, seem to be more virulent. Therefore, they could be considered as indicators of the infection potential of an isolate. Presence of lepA, lidA, ralF, rtxA and IvhB virulence genes is essential for the existence and growth of L. pneumophila in macrophages, for avoidance of phagosome acifidication and lysosome fusion and is necessary for instruction of apoptosis in human macrophages $[29,30]$.

\section{Conclusions}

In conclusion, we identified a large number of positive samples (12\%) in L. pneumophila isolated from BAL samples of patients with RTIs in Iranian health centers. Marked sexual and age-dependent variation in the distribution of $L$. pneumophila were also found. Higher levels of health care and diagnostics should be performed on elder male patients with clinical signs of fever, cough, dyspnea, chest pain, headache and diarrhea who are referred to hospitalization in cold months of the year. In fact, sex, season and certain clinical signs are risk factors for legionellosis caused by L. pneumophila. In an overall view, bacterial strains of our study harbored several virulence factors i.e. lepA, lidA, ralF, rtxA and IvhB. Therefore, virulent $L$. pneumophila should be diagnosed rapidly and carefully. This is the first molecular identification of virulence factors in L. pneumophila strains of RTIs in Iran. Our results represents higher amounts of lidA (50\%) and ralF (27.77\%) virulence factors in bacterial isolates. More complementary studies in larger groups of $L$. pneumophila strains are necessary to confirm our finding.

\section{Competing interests}

The authors declare that they have no competing interests.

\section{Author's contribution}

All authors were participated on sample collection and DNA extraction. The primers sequence alignment, writing and drafting the manuscript were performed by FK, FAF and AD. All authors read and approved the final manuscript.

\section{Acknowledgements}

The authors would like to Thank Dr. Abbas Doosti, Dr. Reza Mirnezhad, Dr. Reza Ranjbar and Dr. Roya Habibian for their clinical support. The authors would also like to acknowledge all of the staff members of the Biotechnology Research Center of Islamic Azad University of Shahrekord Branch, Iran, for their support and contribution to this study. 


\section{References}

1. Bettering the Evaluation And Care of Health (BEACH) study: URTI / bronchosinusitis in general practice. Australian Institute of Health and Welfare General Practitioner Statistics and Classification Centre, University of Sydney [Westmead Hospital's Family Medicine Research Centre]. March 2005.

2. Muder RR, Yu VL: Infection due to Legionella species other than L. pneumophila. Clin Infect Dis 2002, 35: 990-998.

3. Marston BJ, PlouffeJF, FileTM, HackmanBA, SalstromSJ, LipmanHB, KolczakMS, Breiman RF: Incidence of communityacquired pneumonia requiring hospitalization-results of a population-based active surveillance study in Ohio. Arch Intern Med 1997, 157: 1709-1718.

4. Lück C: Legionella: a case for culture. Indian J Med Res 2010, 131: 736-738.

5. Edelstein PH: Legionella. In Manual of Clinical Microbiology, $9^{\text {th }}$ edition. Edited by Murray PR. Washington DC: ASM Press; 2007: 835.

6. Tronel H, Hartemann P: Overview of diagnostic and detection methods for legionellosis and Legionella spp. Lett Appl Microbiol 2009, 48: 653-656.

7. Cirillo SL, Bermudez LE, El-Etr SH, Duhamel GE, Cirillo JD: Legionella pneumophila entry gene rtxA is involved in virulence. Infect Immun 2001, 69: 508-517.

8. D'Auria G, Jiménez-Hernández N, Peris-Bondia F, Moya A, Latorre A: Legionella pneumophila pangenome reveals strainspecific virulence factors. BMC Genomics 2010, 11: 181.

9. Doleans-Jordheim A, Akermi M, Ginevra C, Cazalet C, Kay E, Schneider D,Buchrieser C, Atlan D, Vandenesch F, Etienne J, Jarraud S: Growth-phasedependent mobility of the Ivh-encoding region in Legionella pneumophila strain Paris. Microbiol 2006, 152: 3561-3568.

10. Ngeow YF, Suwanjutha S, Chantarojanasriri T, Wang F, Saniel M, Alejandria M, Hsueh PR, Ping-Ing L, Park SC, Sohn JW, Aziah AM, Liu Y, Seto WH, Ngan CC, Hadiarto M, Hood A, Cheong YM. An Asian study on the prevalence of atypical respiratory pathogens in community-acquired pneumonia. Int J Infect Dis 2005, 9: 144-153.

11. Nagalingam NA, Adesiyun AA, Swanston WH, Bartholomew M. Seroprevalence of Legionella pneumophila in Pneumonia Patients in Four Major Hospitals in Trinidad and Tobago. West Indian Med J 2005, 54: 375-378.

12. Amemura-Maekawa J, Kura F, Helbig JH, Chang B, Kaneko A, Watanabe $Y$, Isobe J, Nukina M, Nakajima H, Kawano K,Tada Y, Watanabe H. Working Group for Legionella in Japan. Characterization of Legionella pneumophila isolates from patients in Japan according to serogroups, monoclonal antibody subgroups and sequence types. J Med Microbio/ 2010, 59: 653659.
13. Kaplan V, Angus DC, Griffin MF, Clermont G, Scott-Watson R, LindeZwirble WT. Hospitalized community-acquired pneumonia in the elderly. Age- and sex-related patterns of care and outcome in the United States. Am J Respir Crit Care Med 2002, 165: 766772.

14. Sopena N, Pedro-Botet L, Mateu L, Tolschinsky G, Rey-Joly C, Sabrià M. Community-acquired legionella pneumonia in elderly patients: characteristics and outcome. J Am Geriatr Soc 2007, 55: 114-119.

15. Fisman DN, Lim S, Wellenius GA, Johnson C, Britz P, Gaskins M, Maher J, Mittleman MA, Spain CV, Haas CN, Newbern C: It's not the heat, it's the humidity: wet weather increaseslegionellosisrisk in the greater Philadelphia metropolitan area. J Infect Dis 2005, 192: 2066-2073.

16. Herrera-Lara S, Fernández-Fabrellas E, Cervera-Juan Á, BlanquerOlivas R: Do seasonal changes and climate influence the etiology of community acquired pneumonia? Arch Bronconeumol 2013, 49: 140-145

17. Ghotaslou R, Yeganeh Sefidan F, Akhi MT, Soroush MH, Hejazi MS: Detection of Legionella Contamination in Tabriz Hospitals by PCR Assay. Adv Pharm Bull 2013, 3: 131-134.

18. Bozzoni M, Radice L, Frosi A, Vezzoli S, Cuboni A, Vezzoli F: Prevalence of pneumonia due to Legionella pneumophila and Mycoplasma pneumoniae in a population admitted to a department of internal medicine. Respiration 1995, 62: 331-5.

19. Yu PY, Lin YE, Lin WR, Shih HY, Chuang YC, Ben RJ, Huang WK, Chen YS, Liu YC, Chang FY, Yen MY, Liu CC, Ko WC, Lin $\mathrm{HH}$, Shi ZY: The high prevalence of Legionella pneumophila contamination in hospital potable water systems in Taiwan: implications for hospital infection control in Asia. Int J Infect Dis 2008, 12: 416-20

20. Chaudhry R, Dhawan B, Dey AB: The incidence of Legionella pneumophila: a prospective study in a tertiary care hospital in India. Trop Doct 2000, 30: 197-200.

21. Azara A, Piana A, Sotgiu G, Dettori M, Grazia Deriu M, Masia MD, Are BM, Muresu E: Prevalence study of Legionella spp. contamination in ferries and cruise ships. BMC Publ Health 2006, 6: 100.

22. Lim W, Macfarlane J, Boswell T, Harrison T, Rose D, Leinonen M, Saikku P: Study of community acquired pneumonia aetiology (SCAPA) in adults admitted to hospital: implications for management guidelines. Thorax 2001, 56: 296-301.

23. Sohn JW, Park SC, Choi YH, Woo HJ, Cho YK, Lee JS, Sim HS, Kim MJ: Atypical pathogens as etiologic agents in hospitalized patients with community-acquired pneumonia in Korea: a prospective multi-center study. J Korean Med Sci 2006, 21: 602607.

24. Chon Lam M, Wei Ang $L$, Tan AL, James $L$, Tai Goh $K$ : Epidemiology and Control of Legionellosis, Singapore. Emerg Infect Dis 2011, 17: 1209-1215. 
25. Joseph CA, Ricketts KD: European Working Group for Legionellalnfections. Legionnaires' disease in Europe 20072008. Euro Surveill 2010, 15: 19493

26. Sopena N, Force L, Pedro-Botet ML, Barrufet P, Sauca G, GarcíaNúñez M, Tolchinsky G, Capdevila JA, Sabrià M: Sporadic and epidemic community legionellosis: two faces of the same illness. Eur Respir J 2007, 29: 138-42.

27. Steinert M, Hentschel U, Hacker J: Legionella pneumophila: an aquatic microbe goes astray. FEMS Microbio/ Rev 2002, 26: 14962.

28. Huang B, Yuan Z, Heron BA, Gray BR, Eglezos S, Bates JR, Savill J: Distribution of 19 major virulence genes in Legionella pneumophila serogroup 1 isolates from patients and water in Queensland, Australia. J Med Microbiol 2006, 55: 993-997.

29. Ingmundson A, Delprato A, Lambright DG, Roy CR: Legionella pneumophila proteins that regulate Rab1 membrane cycling. Nature 2007, 450: 365-370.

30. Bruggemann $H$, Cazalet C, Buchrieser C: Adaptation of Legionella pneumophila to the host environment: role of protein secretion, effectors and eukaryotic-like proteins. Curr Opin Microbiol 2006, 9: 86-94.

\section{Comment on this article:}
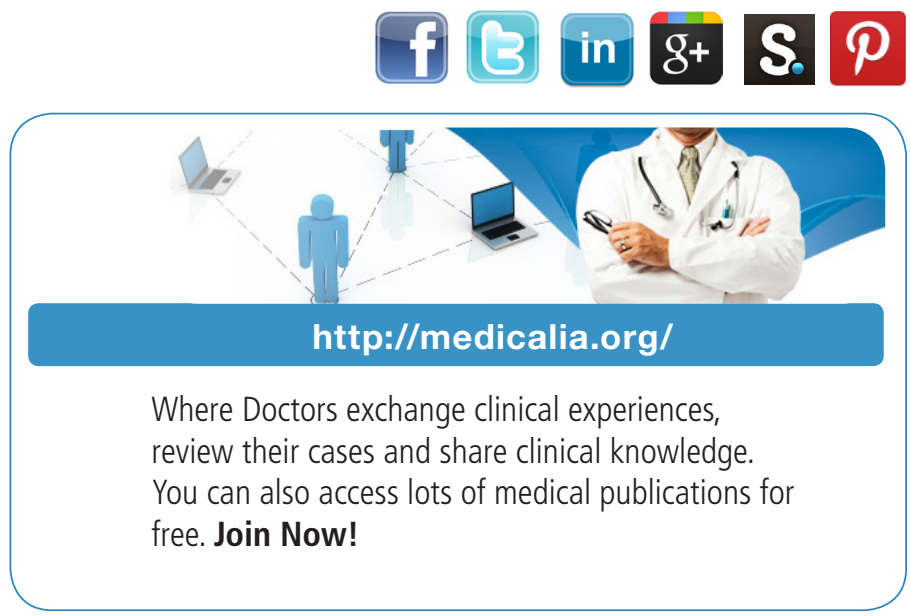

\section{Publish with iMedPub}

\section{http://www.imed.pub}

International Archives of Medicine is an open access journal publishing articles encompassing all aspects of medical science and clinical practice. IAM is considered a megajournal with independent sections on all areas of medicine. IAM is a really international journal with authors and board members from all around the world. The journal is widely indexed and classified Q1 in category Medicine. 